\title{
Exercise and Healthy Eating Intentions and Behaviors among Normal Weight and Overweight/Obese Adults
}

\author{
Stavroula Psouni' ${ }^{1}$, Mary Hassandra ${ }^{2}$, Yannis Theodorakis ${ }^{1}$ \\ ${ }^{1}$ University of Thessaly, Thessaly, Greece \\ ${ }^{2}$ University of Jyväskylä, Jyväskylä, Finland \\ Email: stpsouni@pe.uth.gr \\ Received 15 March 2016; accepted 24 April 2016; published 27 April 2016 \\ Copyright (C) 2016 by authors and Scientific Research Publishing Inc. \\ This work is licensed under the Creative Commons Attribution International License (CC BY). \\ http://creativecommons.org/licenses/by/4.0/

(c) (i) Open Access

\section{Abstract}

Strong evidence suggests that exercise and eating behaviours are strongly linked. Theory of Planned Behaviour is a theoretical framework that has been successfully used to explain and predict both behaviours. The aim of the present study is to explore the constructs of Theory of Planned Behavior (TPB) that better predicts exercise and healthy eating: a) intentions and b) selfreported behaviors among normal weight and overweight/obese adults. Participants were 361 adults in Greece (women: $N=152$ ). According to their BMI scores, they have been grouped into normal weight and overweight/obese. Data were collected with an online questionnaire assessing variables of the theory of planned behavior (TPB) toward exercise and healthy eating intentions and behaviors. Correlations between the variables of TPB and behaviors (healthy eating and exercise) were higher in the normal weight group than in the overweight/obese group. The strongest predictor of intention to exercise was perceived behavioral control for both groups with the overweight/obese group showing higher values in comparison to normal weight group values. The same associations emerged for the prediction of intention for healthy eating behavior. The attitude was also a statistically significant predictor for both groups with higher values in normal weight group. The strongest predictor of exercise behavior was the intention, whereas for eating behavior significant predictors were attitudes, intentions and perceived behavioral control. TPB framework explained both intentions and behaviors for exercise and healthy eating of normal weight and overweight/obese adults. Initial information on which TPB constructs explain better intentions and behaviors by group implied that normal weight group has more positive exercise and healthy eating attitudes and intentions than the overweight/obese group; the behaviors of the overweight/obese group were explained better by perceived behavioral control. The above information can be used to design more effective interventions that aim to produce changes in both behaviors. 


\section{Keywords}

Theory of Planned Behavior, Exercise Behavior, Healthy Eating Behavior, Normal Weight, Overweight

\section{Introduction}

Obesity is a health problem that is related to excessive body fat (Thomas, 2012). Unfortunately, it could have serious consequences associated with more than 30 serious health conditions. Literature shows that main factors affecting obesity are inheritance (Bray \& Bouchard 2014), demographic and lifestyle related (Mogre et al., 2015). Great efforts are undertaken toward understanding the causes and limiting exposure to obesity.

Demographic factors, diet and lack of exercise are associated with obesity (Mogre et al., 2015). There are many factors which influence the healthy eating and exercise levels of an individual. These could be food availability and dietary patterns, daily routines and workload, marketing, cultural and social factors, family, emotions and knowledge. Exercise plays a significant role in the treatment of obesity (Boudreau \& Godin, 2007). Miller \& Miller (2010) assert that obese Americans know the importance of exercise for weight management, but they do not exercise. For many people, emotions play a significant role in eating behaviors. The eating that is related to someone's emotions is defined as emotional eating, and it could lead to obesity problems and is definitely amongst the enemies of healthy eating and exercise (Arnow, 1995). Food marketing and the vast food industry are even claimed to alter perceptions of healthy eating and official regulations on nutrition policies (Nestle, 2013). Furthermore, health behaviors are related to each other. A study by Trudeau, Kristal, Li and Patterson (1998) compared the consumption of fruit and vegetables with healthy behaviors, beliefs, attitudes and intrinsic motivation for healthy eating. They concluded that health-related behaviors were strongly associated with an adequate fruit intake. Finally, demanding jobs have an indirect effect on exercise by lowering perceptions of behavioural control over exercise. However, job strain variables were not related to exercise intentions or behaviour and did not influence consumption of fruit and vegetables (Payne, Jones, \& Harris, 2005).

The Theory of Planned Behavior (TPB) examines the relations between socio-cognitive beliefs and their effects on behavior (Ajzen, 1991). According to the theory, intention and behavior are influenced by attitudes towards behavior, perceived behavioral control and subjective norm. Attitudes express the persons' positive or negative evaluation for the behavior. Intentions are the motivational factors for the behavior. Stronger intentions influence more the performance of behavior. Subjective norms are the belief of the significant others for the behavior of interest. Perceived behavioral control is the perception of how easy or difficult is the behavior (Ajzen, 1988).

Literature shows that TPB can predict health-related behaviors (McEachan, Conner, Taylor, \& Lawton, 2011). Meta-analytic results show the prediction of intentions and behavior quite well (Ajzen, the theory of planned behaviour: reactions and reflections, 2011). Furthermore, TPB has the potential for developing health-related behaviors change interventions. Hardeman, Johnston, Bonetti, Wareham and Kinmonth (2002) reviewed 30 studies which applied TBP to interventions for behavioral change. Half of the studies were effective in intention changing and two-third in behavior changing. Also, the review of Godin and Kok (1996) concludes that TPB is an efficient model for explaining health-related behaviors. The literature provides evidence of the predictive power of the theory in smoking (Hassandra, Vlachopoulos, Kosmidou, Hatzigeorgiadis, Goudas, \& Theodorakis, 2011; Norman, 1999), health (Karvinen et al., 2007) and safe sexual behavior (Albarracin, 2001). The research of Schifter and Ajzen (1985) concluded that TPB has successfully predicted weight reduction, suggesting that individuals with higher perceived behavioral control are more likely to lose weight. An interesting approach by Godin, Bélanger-Gravel, Vohl and Pérusse (2011) indicate that answering a TPB questionnaire could play a major role in subsequent participation in exercise due to cognition perception by the process of answering (mere- measurement effect phenomenon).

Meta-analysis conducted by (Armitage \& Conner, 2001) showed that TPB accounted for $27 \%$ of the variance in health behaviors and $39 \%$ of the variance in intention. The review for fruit and vegetable intake of Guillaumie, Godin and Vezina-Im (2010) suggest that TPB is the preferable theory to predict behavior. Also, in a meta-analysis by McEachan, Conner, Taylor, \& Lawton (2011), exercise and healthy eating behaviors were successfully predicted and explained the variance respectively $23.9 \%$ and $21.2 \%$. In the same study, perceived behavioral control and attitude were the most significant factors affecting behavioral intention. A cross-sectional 
survey of 286 employees in the UK showed that attitudes and subjective norm explained $14 \%$ of intentions to engage in exercise. Perceived behavioral control explained $10 \%$ of attitude, and subjective norm explained $27 \%$ of intention to eat healthily (Payne, Jones, \& Harris, 2004). Research by (Gardner \& Hausenblas, 2005) in 117 overweight women showed for exercise and healthy eating behavior that perceived behavioral control was the only significant predictor of intentions. However, intention did not explain the variance of both behaviors significantly.

Several authors used TPB theory to analyze exercise: Meta-analysis of Hagger, Chatzisarantis and Biddle (2002) showed that behavior of exercise is related with intention and self-efficacy and in turn, the intention is influenced by attitude, subjective norm, perceived behavioral control and past behavior. As reported by the research of Theodorakis (1994) intention for exercise predicted from attitude toward the behavior, perceived behavioral control, attitude strength and role identity whereas exercise behavior predicted from intention, role identity, perceived behavioral control and attitude strength. The results obtained by Ghahremani, Niknami and Nazari (2012) indicated that attitudes, subjective norm, and perceived behavioral control explained $32.8 \%$ of the variance in intention and $15.7 \%$ of the variance in behavior. In their research, Godin, Amireault, Bélanger-Gravel, Vohl and Pérusse (2009) have also found that the overall efficacy of TBP was 59\% in the prediction of intention and $41 \%$ in the prediction of behavior in obese individuals. In the research of Boudreau and Godin (2007), perceived behavioral control, attitude and past behavior explained $73 \%$ of the variance in intention in a sample of obese individuals. In the review of Rhodes and Dickau (2013), intention was the primary determinant of exercise behavior. The proximal moderator of intention was intention stability and was followed by anticipated regret, conscientiousness, perceived control, planning, extraversion and environmental proximity. The results offered by Catellier and Yang (2013) reported lower intentions to exercise from individuals who are in the negative affect condition, that group also showed lower attitudes.

Furthermore, considerable research has been done in the field of healthy eating using TPB. TPB theory and social cognitive theory are the most preferable to predict behavior and explain intention for fruit and vegetable intake (Guillaumie, Godin, \& Vezina-Im, 2010). According to Ajzen and Manstead (2007), an approach based on the theory of planned behavior suggests that intentions and perceived behavioral control predict the behavior of low-fat diet and intentions are predicted by attitudes and subjective norm. As reported by Conner, Norman and Bell (2002), healthy eating intentions were predicted by attitudes, perceived behavioral control, and past behavior, whereas, healthy eating behavior was predicted by intentions. In the paper of Povey, Conner, Sparks, James and Shepherd (2000), which studied TPB and healthy eating in a sample of 235 participants showed that $42 \%$ of intentions variance and $15 \%$ of behavior variance was explained by the TPB constructs. Another research involving 735 young adults demonstrated that TPB constructs explained $52 \%$ of the decision to eat healthily variance with perceived behavioral control and subjective norm being the strongest predictors ( $\AA$ strøm \& Rise, 2001).

Nevertheless, there is a lack of studies comparing normal weight and overweight/obese participants exploring the predictability of TPB on both exercise and healthy eating behaviors. The present paper explores the TPB constructs regarding healthy eating and exercise behavior among normal weight and overweight individuals. Information about the stronger TPB determinants for both behaviors separately for normal and overweight individuals can feed the design of future more successful interventions for behavior change, tailored to the needs of the specific group. It should note that present study's' data are part of a data set of a previously published paper which aimed to identify and characterize the patterns of psychological (well-being, body image, self-control) and behavioral characteristics (exercise and eating habits), in relation to body mass index (Psouni, Hassandra, \& Theodorakis, 2016). Results showed that participants with the lower BMI values had a healthier profile regarding exercise and eating behaviors, and more positive scores in psychological variables, whereas, participants with the higher BMI values had a less healthy profile regarding exercise and eating behaviors, and lower scores in psychological variables.

\section{Aims}

The objectives of the present study were to explore the constructs of TPB that better predict: a) intention and b) self-reported exercise and healthy eating behavior of normal weight and overweight/obese participants.

\section{Methods}

\subsection{Participants}

The total number of participants were 361 (67.3\% were female). The majority of the participants were $68.6 \%$ 
single, $28.1 \%$ married and $3.2 \%$ in a relationship. The average age of the participants was $36.37 \pm 11.98$ years and the mean period of sports activity involvement was $7.38 \pm 8.45$ years. Body mass index was calculated using self-reported weight and height data using the type (weight/height ${ }^{2}$ ). The weight status of the individuals was classified as follows: a) normal weight $<24.9 \mathrm{~kg} / \mathrm{m}^{2}$ and b) overweight/obese $>25 \mathrm{~kg} / \mathrm{m}^{2}$. Overall, $51.3 \%$ of the participants were normal weight and $48.7 \%$ were overweight/obese.

\subsection{Procedure}

The questionnaires were self-reported and completed online. Participants were selected randomly. They all live in Greece. Furthermore, participants completed a consent form in which they were assured of anonymity and that they were free to withdraw from the study whenever they wanted.

\subsection{Measures}

Participants completed a questionnaire assessing the components of the TPB for healthy eating and exercise, in addition to the self-reported corresponding behaviors.

Self-reported exercise behavior. Participants completed the Godin-Shephard (1985) Leisure-Time Physical Activity Questionnaire (LTPA). They answered three questions asking about the time which is spent in exercise participation in the last seven days. Responses were given to describe what exercise, mild, moderate and heavy intensity in minutes participants did during the week. Score was obtained by multiply the minutes of exercise with 9 for strenuous exercise, 5 for moderate exercise and 3 for mild exercise.

Self-reported healthy eating behavior. (EB) was measured via Eating Behavior Questionnaire (EBQ; Bebetsos, Theodorakis, Laparidis, \& Chroni, 2000; Bebetsos, Chroni, \& Theodorakis, 2002). Questions recorded how often the participants consumed healthy and unhealthy foods in the previous month. EBQ consists of 33 items; 22 of them assess healthy eating behaviors e.g., "How many times last month did you eat fresh vegetables?" and 11 items assess unhealthy eating behaviors e.g., "How many times last month did you drink soft drinks?" Score was calculated by subtracting the scores of the unhealthy behaviors from the scores of healthy behaviors.

TPB measures of exercise and healthy eating. The questionnaires assessed the four variables of TPB for exercise and healthy eating behavior according to the constructs of Ajzen (2002). The questionnaire has been adapted for Greek population by (Theodorakis, 1994).

Intention for exercise and healthy eating. Intention was measured via 3 questions for each behavior: "I intend to exercise/eat healthily": very likely-very unlikely. "I am determined to exercise/eat healthily": absolutely yes-absolutely no; "I'll try to exercise/eat healthily": absolutely right-absolutely wrong. Responses were given on a scale from 1 to 7 . Higher scores indicated higher levels of behavioral intention.

Attitude for exercise and healthy eating. The attitude was measured via responses to six bipolar opposite paired adjectives with a response scale ranging from 1 to 7: "good-bad", "unpleasant-pleasant", "useful-useless", "unattractive-attractive", "boring-interesting" and "healthy-unhealthy". The higher the score, the more positive the attitude is.

Subjective norm for exercise and healthy eating. This was measured via three questions on a $1-7$ scale e.g., "Many important persons for my life believe that I should exercise for next month": likely-unlikely and "If I exercise/eat healthy for next month, many important people will...": agree-disagree. Higher scores indicated higher levels of the subjective norm.

Perceived behavioral control for exercise and healthy eating. This was measured via three items, with responses ranging from 1 to 7 : "It is totally up to me whether I will exercise/eat healthily or not": strongly disagree-strongly agree; "For me exercising/eating healthy is ...": very difficult-very easy; and "I am very confident that I shall exercise/eat healthily": completely correct-completely wrong. Higher scores indicated higher perceived behavioral control.

\subsection{Data Analysis}

The analysis was performed using SPSS software, version 20. Cronbach's alpha, t-test, and correlations were used for the initial descriptive analysis. The main analysis is hierarchical linear regression (Gelman, 2006) where the variables are entered in blocks into the regression. Four regression analyses were performed: Two using as the dependent variable the behavioral intention for exercise and healthy eating and the next two using as 
the dependent variable the self-reported exercise and healthy eating behaviors.

\section{Results}

\subsection{Descriptive Statistics}

Descriptive statistics along with Cronbach's $\alpha$ is presented in Table 1. The results for internal consistency of each of the four measures (attitude, intention, perceived behavioral control, and subjective norm) show that 3 of them have relatively high internal consistency. The only measure that showed low internal consistency is the subjective norm with 0.34 score on the Cronbach's alpha test statistic on both exercise and healthy eating measures.

For the needs of the analysis, the sample was split into two groups based on BMI values: normal weight with BMI $<24.9 \mathrm{~kg} / \mathrm{m}^{2}(\mathrm{~N}=185)$ and overweight/obese with BMI $>25 \mathrm{~kg} / \mathrm{m}^{2}(\mathrm{~N}=176)$. The mean BMI of the normal weight groups was $21.75 \mathrm{~kg} / \mathrm{m}^{2}$, and that of the overweight/obese group was $30.15 \mathrm{~kg} / \mathrm{m}^{2}$. The values of the self-reported behaviors as measured by leisure time and healthy eating questionnaires and tested through t-test, were statistically significant between the two groups. As was expected normal-weight individuals had higher values in leisure time activity as like in healthy eating (Table 1).

There were non-statistical significant differences in the attitude and subjective norm towards exercise for normal weight and overweight/obese individuals. Intention and perceived behavioral control were statistically significant different between the two groups with the average score of the normal weight group being higher than that of the overweight/obese group. All the TPB scores for healthy eating were statistically significantly higher in normal-weight than in overweight/obese groups in the same way as the rest of the variables, except subjective norms (Table 1). Correlation analysis results are presented in Table 2. All variables were correlated to the expected directions for both groups and measures except subjective norms and BMI.

\subsection{Prediction of Exercise and Healthy Eating Intentions}

Based on the first aim of the study, in order to explore TPB as a framework for understanding exercise and healthy eating intentions for normal weight individuals and overweight individuals, two hierarchical multiple regressions were conducted: one with exercise intention as the dependent variable and the other with healthy eating intention as the dependent variable. TPB variables were entered in steps as follows: In the 1st step was entered attitudes and subjective norm and in the 2nd step the perceived behavioral control. The analysis was

Table 1. Means, standard deviations, Cronbach's alpha and group differences.

\begin{tabular}{|c|c|c|c|c|c|c|c|}
\hline & \multicolumn{2}{|c|}{ Normal/weight $(\mathrm{N}=185)$} & \multicolumn{2}{|c|}{ Overweight $(\mathrm{N}=176)$} & \multirow{2}{*}{$\mathrm{t}$} & \multirow{2}{*}{$p$} & \multirow{2}{*}{ Cronbach's o } \\
\hline & Mean & SD & Mean & SD & & & \\
\hline \multicolumn{8}{|l|}{ Exercise } \\
\hline 1. Attitude & 39.42 & 3.80 & 38.71 & 4.93 & 1.53 & 0.12 & 0.78 \\
\hline 2. Intention & 17.85 & 4.29 & 16.96 & 4.61 & 1.89 & 0.05 & 0.88 \\
\hline 3. Perceived behavioral control & 16.76 & 4.99 & 15.37 & 4.97 & 2.63 & 0.00 & 0.91 \\
\hline 4. Subjective norm & 12.96 & 2.77 & 12.63 & 2.87 & 1.11 & 0.25 & 0.34 \\
\hline \multicolumn{8}{|l|}{ Healthy Diet } \\
\hline 1. Attitude & 39.36 & 3.66 & 38.26 & 4.46 & 2.56 & 0.01 & 0.77 \\
\hline 2. Intention & 17.94 & 3.75 & 16.66 & 4.71 & 2.85 & 0.00 & 0.91 \\
\hline 3. Perceived behavioral control & 17.24 & 3.56 & 15.08 & 4.49 & 5.07 & 0.00 & 0.87 \\
\hline 4. Subjective norm & 12.78 & 2.56 & 13.03 & 5.39 & 0.58 & 0.56 & 0.34 \\
\hline \multicolumn{8}{|l|}{ Behaviors } \\
\hline Leisure time activity & 42.09 & 22.5 & 32.80 & 26.37 & 4.28 & 0.00 & \\
\hline Healthy eating & 0.46 & 0.65 & 0.31 & 0.73 & 1.92 & 0.05 & \\
\hline BMI & 21.75 & 1.87 & 30.15 & 4.21 & -24.68 & 0.00 & \\
\hline Exercise & & & & & & & \\
\hline
\end{tabular}


Table 2. Correlations for physical activity and healthy eating TPB questionnaires for normal weight and overweight individual.

\begin{tabular}{|c|c|c|c|c|c|c|c|c|c|c|c|c|}
\hline & \multicolumn{6}{|c|}{ Normal weight } & \multicolumn{6}{|c|}{ Overweight } \\
\hline & 1 & 2 & 3 & 4 & 5 & 6 & 1 & 2 & 3 & 4 & 5 & 6 \\
\hline \multicolumn{13}{|l|}{ Variables for Physical Activity } \\
\hline 1. Attitude & & & & & & & & & & & & \\
\hline 2. Intention & $0.52^{* *}$ & & & & & & $0.36^{* *}$ & & & & & \\
\hline 3. Perceived behavioral control & $0.53^{* *}$ & $0.83^{* *}$ & & & & & $0.30^{* *}$ & $0.76^{* *}$ & & & & \\
\hline 4. Subjective norm & 0.10 & 0.03 & 0.07 & & & & 0.07 & 0.04 & 0.04 & & & \\
\hline 5. BMI & 0.03 & 0.02 & 0.03 & 0.10 & & & -0.05 & -0.02 & 0.06 & 0.01 & & \\
\hline 6. Leisure Time Activity & $0.33^{* *}$ & $0.44^{* *}$ & $0.46^{* *}$ & 0.05 & 0.03 & & $0.16^{*}$ & $0.30^{* *}$ & $0.36^{* *}$ & 0.03 & $-0.16^{*}$ & \\
\hline 7. Eating Behavior & $0.23^{* *}$ & $0.20^{* *}$ & $0.24^{* *}$ & 0.01 & $0.18^{*}$ & $0.21^{* *}$ & $0.26^{* *}$ & $0.18^{*}$ & $0.19^{*}$ & 0.02 & 0.11 & 0.11 \\
\hline
\end{tabular}

Variables for Healthy Eating

1. Attitude

2. Intention

$0.48^{* *}$

3. Perceived behavioral control

$0.51^{* *} \quad 0.72^{* *}$

4. Subjective norm

$0.20^{* *} \quad 0.14 \quad 0.09$

5. BMI

6. Leisure Time Activity

$\begin{array}{llll}0.11 & 0.07 & 0.07 & 0.16^{*}\end{array}$

7. Eating Behavior

$\begin{array}{llll}0.19^{* *} & 0.17^{* *} & 0.25^{* *} & 0.02\end{array}$

$0.27^{* *} \quad 0.43^{* *}$

$0.45^{* *} \quad 0.06$

0.03

${ }^{* *} p<0.001 ;{ }^{*} p<0.005$.

performed after splitting the data into the two groups of participants: the normal weight and overweight group. Results of the analysis are displayed in Table 3. In step 1, attitudes significantly predicted exercise intention, accounting for $28 \%\left(F_{(3,181)}=36.58, p<0.001\right)$ for the normal weight individuals and $12 \%$ of the variance $\left(F_{(1,173)}=12.74, p<0.001\right)$ of the overweight individuals. In step 2, perceived behavioral control explained $42 \%$ of the variance in normal weight individuals $\left(F_{(3,181)}=146.53, p<0.001\right)$ and $49 \%$ in overweight individuals $\left(F_{(2,172)}=87.05, p<0.001\right)$ Overall, the results showed that perceived behavioral control was the most important factor for the prediction of exercise intention on both weight groups.

The second hierarchical regression was conducted to predict intentions to eat healthily. The healthy eating intention was the dependent variable and the TBP variables of attitude, subjective norm and perceived behavioral control were designated as predictors and entered in steps as in the previous analysis. The results are displayed in Table 4. In the first step, attitudes accounted for $23 \%$ of normal weight individuals $\left(F_{(1,183)}=27.76, p<\right.$ $0.001)$ and $11 \%\left(F_{(1,174)}=11.32, p<0.001\right)$ for overweight/obese. In the second step, perceived behavioral control accounted for $31 \%$ of normal weight individuals $\left(F_{(2,182)}=71.53, p<0.001\right)$ and $47 \%$ for overweight/obese $\left(F_{(2,173)}=80.22, p<0.001\right)$. As well as the analysis of exercise, the results showed that perceived behavioral control was the most important factor for the prediction of healthy eating intention on both weight groups.

\subsection{Prediction of Exercise and Healthy Eating Behavior}

In order to explore TPB as a framework for understanding the actual behaviors of exercise and healthy eating for normal weight and overweight individuals, TPB variables were entered in hierarchical multiple regressions steps as follows: In the first step attitude and subjective norm were entered, in the second step behavioral intention was entered and in the third step the variable of perceived behavioral control.

The third hierarchical regression analysis was conducted to predict exercise behavior (Table 5). Attitude and subjective norm were the first variables entered in the analysis accounting for $11 \%$ normal weight $\left(F_{(1,183)}=\right.$ $11.54, p<0.001)$ and $0.3 \%$ for overweight/obese participants $\left(F_{(1,174)}=2.99, p<0.001\right)$. In the second step, added intentions accounted for $10 \%$ of the variance of normal weight $\left(F_{(2,182)}=16.65, p<0.001\right)$ and $7 \%$ for the variance of overweight/obese $\left(F_{(2,173)}=6.80, p<0.001\right)$. Finally, in step 3 perceived behavioral control was a significant predictor for both groups, accounting for $2 \%$ of normal weight $\left(F_{(3,181)}=14.34, p<0.001\right)$ and $3 \%$ of 
Table 3. Prediction of intention to exercise for normal weight and overweight individuals.

\begin{tabular}{|c|c|c|c|c|c|c|}
\hline \multirow{2}{*}{ Predictor } & \multicolumn{3}{|c|}{ Normal-weight } & \multicolumn{3}{|c|}{ Overweight } \\
\hline & $\mathrm{b}$ & $\mathrm{SE} b$ & $\beta$ & $\mathrm{b}$ & $\mathrm{SE} b$ & $\beta$ \\
\hline \multicolumn{7}{|l|}{ Step 1} \\
\hline Attitude & 0.60 & 0.07 & $0.53^{* *}$ & 0.33 & 0.06 & $0.35^{* *}$ \\
\hline Subjective Norm & 0.14 & 0.09 & -0.09 & 0.11 & 0.11 & 0.07 \\
\hline \multicolumn{7}{|l|}{ Step 2} \\
\hline Attitude & 0.12 & 0.05 & $0.10^{*}$ & 0.12 & 0.04 & $0.13^{*}$ \\
\hline Subjective Norm & 0.01 & 0.06 & 0.01 & 0.14 & 0.07 & 0.08 \\
\hline Perceived behavioral control & 0.67 & 0.04 & $0.77^{* *}$ & 0.67 & 0.04 & $0.72^{* *}$ \\
\hline
\end{tabular}

Note: For normal weight: $\mathrm{R}^{2}=0.70$, for step $1: \Delta \mathrm{R}^{2}=0.28$, for step $2: \Delta \mathrm{R}^{2}=0.42$; for overweight: $\mathrm{R}^{2}=0.60$, for step $1: \Delta \mathrm{R}^{2}=0.12$, for step 2: $\Delta \mathrm{R}^{2}=$ $0.49 ;{ }^{* *} p<0.001,{ }^{*} p<0.01$.

Table 4. Prediction of intention to heating behavior for normal weight and overweight individuals.

\begin{tabular}{|c|c|c|c|c|c|c|}
\hline \multirow{2}{*}{ Predictor } & \multicolumn{3}{|c|}{ Normal-weight } & \multicolumn{3}{|c|}{ Overweight } \\
\hline & $\mathrm{b}$ & $\mathrm{SE} b$ & $\beta$ & $\mathrm{b}$ & SE b & $\beta$ \\
\hline \multicolumn{7}{|l|}{ Step 1} \\
\hline Attitude & 0.48 & 0.06 & $0.47^{* *}$ & 0.34 & 0.07 & $0.32^{* *}$ \\
\hline Subjective Norm & 0.07 & 0.09 & 0.04 & 0.10 & 0.06 & 0.11 \\
\hline \multicolumn{7}{|l|}{ Step 2} \\
\hline Attitude & 0.13 & 0.06 & $0.13^{*}$ & 0.11 & 0.05 & $0.10^{*}$ \\
\hline Subjective Norm & 0.07 & 0.07 & 0.05 & 0.02 & 0.04 & 0.02 \\
\hline Perceived behavioral control & 0.68 & 0.06 & $0.65^{* *}$ & 0.75 & 0.05 & $0.72^{* *}$ \\
\hline
\end{tabular}

Note: For normal weight: $\mathrm{R}^{2}=0.54$, for step 1: $\Delta \mathrm{R}^{2}=0.23$, for step 2: $\Delta \mathrm{R}^{2}=031$; for overweight: $\mathrm{R}^{2}=0.58$, for step 1: $\Delta \mathrm{R}^{2}=0.11$, for step 2: $\Delta \mathrm{R}^{2}=$ $0.47 ;{ }^{* *} p<0.001,{ }^{*} p<0.01$.

Table 5. Prediction of exercise behavior for normal weight and overweight individuals.

\begin{tabular}{|c|c|c|c|c|c|c|}
\hline \multirow{2}{*}{ Predictor } & \multicolumn{3}{|c|}{ Normal-weight } & \multicolumn{3}{|c|}{ Overweight } \\
\hline & $\mathrm{b}$ & $\mathrm{SE} b$ & $\beta$ & $\mathrm{b}$ & $\mathrm{SE} \mathrm{b}$ & $\beta$ \\
\hline \multicolumn{7}{|l|}{ Step 1} \\
\hline Attitude & 1.97 & 0.41 & $0.33^{* *}$ & 0.98 & 0.41 & $0.18^{*}$ \\
\hline Subjective norm & 0.14 & 0.57 & 0.02 & -0.25 & 0.69 & -0.02 \\
\hline \multicolumn{7}{|l|}{ Step 2} \\
\hline Attitude & 0.76 & 0.46 & 0.12 & 0.41 & 0.42 & 0.07 \\
\hline Subjective Norm & 0.42 & 0.54 & 0.05 & -0.45 & 0.66 & -0.04 \\
\hline Intention & 0.01 & 0.41 & $0.38^{* *}$ & 1.65 & 0.44 & $0.28^{* *}$ \\
\hline \multicolumn{7}{|l|}{ Step 3} \\
\hline Attitude & 0.51 & 0.47 & 0.08 & 0.35 & 0.41 & 0.06 \\
\hline Subjective Norm & 0.57 & 0.53 & 0.07 & -0.25 & 0.66 & -0.02 \\
\hline Intention & 0.81 & 0.63 & 0.15 & 0.43 & 0.64 & 0.07 \\
\hline Perceived behavioral control & 0.35 & 0.55 & $0.29^{* *}$ & 1.51 & 0.59 & $0.28^{*}$ \\
\hline
\end{tabular}

Note: For normal weight: $\mathrm{R}^{2}=0.24$, for step 1: $\Delta \mathrm{R}^{2}=0.11$, for step 2: $\Delta \mathrm{R}^{2}=0.10$, for step 3: $\Delta \mathrm{R}^{2}=0.02$; for overweight: $\mathrm{R}^{2}=0.14$, for step $1: \Delta \mathrm{R}^{2}=$ 0.03 , for step 2: $\Delta \mathrm{R}^{2}=0.07$, for step $3: \Delta \mathrm{R}^{2}=0.03 ;{ }^{* *} p<0.001,{ }^{*} p<0.01$.

overweight/obese participants $\left(F_{(3,172)}=6.90, p<0.001\right)$.

The results of the 4 th hierarchical regression analysis, for predicting healthy eating behavior are displayed in Table 6. In the first step of analysis, attitude and subjective norm contributed significantly to $8 \%$ of normal 
weight participants $\left(F_{(1,183)}=7.64, p<0.001\right)$ and $13 \%$ for overweight $/$ obese $\left(F_{(1,174)}=13.47, p<0.001\right)$. In the second step, intention contributed significantly $11 \%$ for both normal weight $\left(F_{(2,182)}=14.50, p<0.001\right)$ and $10 \%$ for overweight/obese $\left(F_{(2,173)}=18.30, p<0.01\right)$. Finally, perceived behavioral control was a significant predictor, $3 \%$ for normal weight $\left(F_{(3,181)}=13.26, p<0.001\right)$ and $7 \%$ for overweight/obese $\left(F_{(3,172)}=19.77, p<0.001\right)$.

\section{Discussion}

As expected, results showed that normal weight individuals exercised more and eat healthier than those who are overweight. Furthermore, normal weight participants have higher scores in TPB variables than overweight/obese participants. These higher scores in accordance with the statement of Connolly, Romano, \& Patruno (1998), lead to the conclusion, that the treatment of obesity is a proper balance of caloric expenditure with calorie intake behaviors. Therefore, the best results in obesity treatment are achieved by a combination of diet and exercise behaviors (Clark, 2015). For maintaining weight loss successfully at least one year is needed of increase in exercise and decreased calorie intake. Additionally, eating breakfast, self-monitoring weight and maintaining a proper eating pattern during the weekdays and weekends is necessary (Wing \& Phelan, 2005).

The score of attitudes towards exercise in normal-weight participants is slightly higher than overweight/obese group. The results obtained for both groups indicate that they consider exercise as a good thing: pleasant, useful, attractive, interesting and healthy. Similarly, in their research, Miller \& Miller (2010) reported that there was no significant difference between normal weight and overweight/obese adults' attitudes towards exercise. The results indicate that both groups are likely and rather determined to exercise and will try to do so. We assume that for a person with normal weight there is a more positive confidence of control and overcoming the difficulties of engaging, in both behaviors. In addition, the results of the healthy diet measures corroborate the literature in the field of healthy eating. More positive attitudes about healthy eating were more evident in females, higher social classes, non-smokers, normal body weight individuals, and increased according to age (Hearty, McCarthy, Kearney, \& Gibney, 2007).

The highest correlations are found between the following three measures: intention, attitude and perceived behavioral control for the normal weight group regarding both exercise and healthy eating. Concerning the exercise behavior, all correlation coefficients are statistically significant and above the moderate level for the normal weight group. For obese/overweight group considering exercise behavior, even though the correlation coefficients between the self-reported exercise behavior, intention and attitude are strongly significant and positive, the association is rather weak.

Table 6. Prediction of eating behavior for normal weight and overweight individuals.

\begin{tabular}{|c|c|c|c|c|c|c|}
\hline \multirow{2}{*}{ Predictor } & \multicolumn{3}{|c|}{ Normal-weight } & \multicolumn{3}{|c|}{ Overweight } \\
\hline & $\mathrm{b}$ & $\mathrm{SE} \mathrm{b}$ & $\beta$ & $\mathrm{b}$ & $\mathrm{SE} b$ & $\beta$ \\
\hline \multicolumn{7}{|l|}{ Step 1} \\
\hline Attitude & 0.05 & 0.01 & $0.27^{* *}$ & 0.59 & 0.01 & $0.10^{* *}$ \\
\hline Subjective Norm & 0.01 & 0.02 & 0.01 & 0.01 & 0.01 & 0.11 \\
\hline \multicolumn{7}{|l|}{ Step 2} \\
\hline Attitude & 0.01 & 0.01 & 0.09 & 0.04 & 0.01 & $0.24^{* *}$ \\
\hline Subjective Norm & 0.01 & 0.02 & 0.01 & 0.01 & 0.01 & 0.06 \\
\hline Intention & 0.06 & 0.02 & $0.39^{* *}$ & 0.05 & 0.01 & $0.34^{* *}$ \\
\hline \multicolumn{7}{|l|}{ Step 3} \\
\hline Attitude & 0.01 & 0.06 & 0.03 & 0.03 & 0.01 & $0.21^{* *}$ \\
\hline Subjective Norm & 0.01 & 0.01 & -0.01 & 0.01 & 0.01 & 0.05 \\
\hline Intention & 0.04 & 0.02 & $0.21^{*}$ & 0.01 & 0.01 & 0.04 \\
\hline Perceived behavioral control & 0.05 & 0.02 & $0.27^{* *}$ & 0.06 & 0.02 & $0.41^{* *}$ \\
\hline
\end{tabular}

Note: For normal weight: $\mathrm{R}^{2}=0.22$, for step $1: \Delta \mathrm{R}^{2}=0.08$, for step $2: \Delta \mathrm{R}^{2}=0.11$, for step $3: \Delta \mathrm{R}^{2}=0.03$; for overweight: $\mathrm{R}^{2}=0.31$, for step $1: \Delta \mathrm{R}^{2}=$ 0.13 , for step 2: $\Delta \mathrm{R}^{2}=0.10$, for step 3: $\Delta \mathrm{R}^{2}=0.07 ;{ }^{* * *} p<0.001, \stackrel{*}{p} p<0.01$. 
Regarding healthy eating, the situation is relatively the same; however, the level of association is even weaker. Therefore, the level of actual exercise is very weakly related to healthy eating intention and attitude. Healthy eating behavior is more highly correlated to healthy eating positive intention and attitude. However, these correlation coefficients, though strongly significant, are below the intermediate correlation level, and therefore show a weak association between the actual status of healthy eating behavior and intention, as like attitude towards healthy eating and both behaviors. However, Payne, Jones, and Harris (2004) in their research pointed out those attitudes had the highest correlation with the intention to engage in both exercise and healthy eating.

There are several interesting observations for the group of overweight/obese people in the correlation results table. The first and expected outcome is the negative correlation between the actual level of exercise and BMI, even though weak and moderately significant. This means that the higher the weight of the participant, the less exercise done. As reported by Godin, Bélanger-Gravel, and Nolin (2008), BMI has a negative influence on leisure time physical activity. The other interesting result is the fewer strong correlations for the group of overweight/obese people. That shows instability between behaviors, attitudes and intentions. For example, the low correlations between attitudes and behaviors for both exercise and healthy eating shows that overweight/obese participants have high attitudes for healthy eating and exercise, but they don't apply those behaviors in practice. The same is happening with the correlations of attitudes and intentions, overweight/obese participants appeared relatively higher attitudes but lower intentions scores. Those points will be helpful for the development of intervention programs by giving emphasis to the implementation of exercise and healthy diet behaviors, as like the stages of behavior change.

\subsection{Prediction of Exercise and Healthy Eating Intentions}

The model for exercise and healthy eating intention has a precise fit for both groups. The TPB variables (attitudes, perceived behavioral control, and subjective norm) were significant predictors of intentions. Similarly, the research of Conner et al. (2002) showed that intentions to eat healthily were predicted by attitudes, perceived behavioral control and perceived past behavior. Attitude was a statistically significant factor in the first step, but subjective norm was not. In the first step, the variables accounted for almost double score for the normal weight compared with the score of overweight/obese participants in both exercise and healthy eating prediction of intention. Results confirmed that attitude to exercising and healthy eating has a considerably significant effect on the intention, which was stronger in the normal weight group compared to the overweight/obese group. These findings are in accordance with the study of Deforche, De Bourdeaudhuij and Tanghe (2006) suggest that overweight adolescents showed a more negative attitude towards exercise and lower sports participation, in comparison with normal weight adolescents.

In the second step of the regression, perceived behavioral control had the stronger effect in the prediction of intention for both groups. These results are in accordance with the results of Boudreau and Godin (2007) who indicated that attitude and perceived behavioral control explained $66 \%$ of the intention to engage in the exercise of overweight/obese individuals. In addition, studies predicting healthy eating intention among adolescents groups describe similar results. The intention was strongly predicted by perceived behavioral control (Plotnikoff, Lubans, Costigan, \& McCargar, 2013) and attitudes (Grønhøj, Bech-Larsen, Chan, \& Tsang, 2013; Øygard \& Rise, 1996). Furthermore, our study showed that perceived behavioral control accounted less in the prediction of the dependent variable for the normal weight group than the overweight/obese individuals. That means that overweight/obese individuals behaviors are affected more by the function of control beliefs and they have lower behaviours of exercise and healthy eating. An explanation of these findings is that overweight people have lower self-esteem (McClure, Tanski, Kingsbury, Gerrard, \& Sargent, 2010) and lower self-control (Puhl \& Heuer, 2009).

\subsection{Prediction of Exercise and Healthy Eating Behaviors}

The variables of attitude, intention and perceived behavioral control were designated as predictors of exercise and healthy eating behaviors, as the TPB model suggests. The ability of the attitude variable to predict both behaviors was strong enough. As was expected, higher values appeared in the normal weight group for prediction of exercise but for the prediction of healthy eating higher values appeared in the overweight/obese group. It can be concluded that overweight/obese participants are more conversant with healthy eating behavior than exercise. Results showed that attitude and intention were also significant factors for the prediction of both behaviors as 
like perceived behavioral control. Subjective norm was the only factor that was not a strong predictor of both exercise and healthy eating behaviors. According to Theodorakis (1994), that could be explained because the influence of subjective norm may depend on the age of participants.

The explanatory variance percentages of exercise prediction are almost double for the normal weight group than the overweight/obese group. Obese/overweight individuals answered that they exercised less, and they have the lowest attitude toward exercise. This explains as was expected the low scores on attitudes towards exercise. Intention to be physically active has a considerable significant effect on the actual exercise behavior, and this effect is much stronger in the normal weight group compared to the overweight/obese group. In the third step of the regression, perceived behavioral control was added and significantly affected the prediction of behaviours for both groups, but was slightly higher in overweight/obese group. As was referred above, overweight/obese individuals' behaviors are affected more by the function of control beliefs.

A similar study by Godin et al. (2009) for the prediction of exercise behavior among overweight/obese individuals indicates that intention is the primary predictor. Perceived behavioral control contributes to prediction only when the environment is perceived as favorable to exercise. The results of another study with a sample of overweight/obese participants (mean BMI 27) showed that the main significant variables for predicting exercise behavior were the intention and perceived behavioral control (Amireault, Godin, Vohl, \& Pérusse, 2008). A possible explanation for lower overweight/obese prediction of exercise behavior is the conclusion of Godin et al. (2009) that obesity is a barrier for a person to exercise regularly. Furthermore, they mention that the common barriers to exercise are the fear of being injured, an inability to record progress, and a lack of motivation and social support. The fact that exercise is proven to have a positive effect on the emotional status of a person (Hyde, Conroy, \& Pincus, 2011) constitutes a vicious circle for obese people who do not exercise.

Literature has proposed the efficacy of the TPB as a predictor of healthy eating diet (Armitage \& Cornner, 1999). The current findings are quite unexpected for healthy eating behavior. The overweight/obese group showed higher explanatory variance percentages in the prediction of behavior than normal weight group. A possible explanation could be that overweight/obese persons are more obsessed with their diet. An explanation might be that as in the US maybe in Greece also, marketing efforts are directed mostly towards the promotion of excessive food intake and less to the promotion of exercise. This is considered as one of the causes of the obesity epidemic (Hill, 1998). Therefore, overweight/obese individuals are probably more careful than those who have normal weight.

Armitage and Cornner (1999) found that TPB predicted effectively low-fat eating diet behavior. In our study, in both groups all the entered TBP variables except subjective norm are capable of explaining the changes in exercise and healthy eating behavior. Explanatory variance percentages for eating behavior were stronger for the overweight/obese group. The opposite is happening in the prediction of exercise behavior, where were stronger for the normal-weight group. Research in older adults have shown that healthy eating behavior (vegetable consumption) is explained by $18 \%$ of the variance with perceived behavioral control being most important, followed by attitudes and subjective norm (Kim, Reicks, \& Sjoberg, 2003; Sjoberg, Kim, \& Reicks, 2004). Our results imply that interventions aiming to change healthy eating behavior should be based on behavior change techniques targeting attitudes, intentions, and perceived behavioral control. The differences in regression steps in the two groups lead us to the conclusion that interventions for overweight/obese people should give emphasis to develop firstly more positive attitudes, secondly intentions and thirdly perceived behavioral control through appropriate behavior change techniques targeting those constructs. This finding is in accordance with other findings suggesting that targeting formation of implementation intentions in order to increase healthy eating, was effective (Adriaanse, Vinkers, De Ridder, Hox, \& De Wit, 2011; Verplanken \& Faes, 1999).

This study has a number of limitations that must be acknowledged. Firstly, the volunteer participants who responded to the invitation to complete the questionnaire might represent individuals who are already interested in the topic. Secondly, the self-reported height and weight might not give a reliable and accurate BMI score. It has been reported that body measurements are often misestimated by respondents (Rothman, 2008). Thirdly, the assessment of exercise and diet behaviors was also based on self-reported responses. A final limitation is the low score of Chronbach's alpha in the variable of subjective norm. The low Cronbach's' alpha is an important factor for the reliability of the variable of subjective norm and may be the reason for the non-significant influence in prediction. Another explanation, referred in a meta-analysis of TPB, might be that there is a lack of association between subjective norm and intentions (Rivis \& Shereran, 2003). Nevertheless, in other studies as well there was no significant contribution of this construct in predicting exercise behavior (Bozionelos, 1999). 
The purpose of this paper was to gain a better understanding of exercise and healthy eating behaviors regarding differences between normal weight and overweight/obese participants. The present results can be useful for the development of more effective intervention programs aiming to change both behaviors for overweight/obese and normal weight people. Interventions will be more successful if they are targeting determinants of behavior (Guillaumie, Godin, \& Vezina-Im, 2010) and use the most successful behaviour change techniques for that purpose (Michie, Ashford, Sniehotta, Dombrowski, Bishop, \& French, 2011).

In general, the results confirmed that constructs of TPB can explain exercise and healthy eating intentions and behaviors for both overweight/obese and normal weight people, with lower explanatory power when the model had to explain the self-reported exercise and healthy eating behaviors. According to Rivis and Shereran (2003), attitudes and subjective norm typically accounted for 33\% - 50\% of the variance of intention and intentions typically explain between $19 \%-38 \%$ of behavior variance. Other meta-analyses show that when the intention is predicted from attitude, subjective norm and perceived behavioral control, between $40 \%-50 \%$ of the variance is explained. When behavior is predicted from intention alone or from intention and perceived behavioral control, between $19 \%$ and $38 \%$ of the variance is explained (Sutton, 1998). The lower percentages we have found might be because of the low alpha Cronbach in subjective norms. We suggest that these items in Greek language need to be refined and tested before used again. Replication of the present study to a population with similar characteristics and larger samples might be useful to confirm these findings. Thereafter, it would be useful to test these findings in experimental studies testing the effectiveness of an intervention program designed on these findings.

\section{References}

Adriaanse, M., Vinkers, C., De Ridder, D., Hox, J., \& De Wit, J. (2011). Do Implementation Intentions Help to Eat a Healthy Diet? A Systematic Review and Meta-Analysis of the Empirical Evidence. Appetite, 56, 183-193. http://dx.doi.org/10.1016/j.appet.2010.10.012

Ajzen, I. (1985). From Intentions to Actions: A Theory of Planned Behavior. In J. Kuhl, \& J. Beckmann (Eds.), Action Control, Social Psychology (pp. 11-39). Berlin: Springer. http://dx.doi.org/10.1007/978-3-642-69746-3_2

Ajzen, I. (1988). Attitudes, Personality, and Behavior. Chicago: IL: Dorsey.

Ajzen, I. (2002). Constructing a TpB Questionnaire: Conceptual and Methodological Considerations. http://www.uni-bielefeld.de/ikg/zick/ajzen $\% 20$ construction $\% 20 \mathrm{a} \% 20 \mathrm{tpb} \% 20$ questionnaire.pdf

Ajzen, I. (1991). The Theory of Planned Behavior. Organizational Behavior and Human Decision Processes, 50, $179-121$. http://dx.doi.org/10.1016/0749-5978(91)90020-T

Ajzen, I. (2011). The Theory of Planned Behaviour: Reactions and Reflections. Psychology \& Health, 26, 1113-1127. http://dx.doi.org/10.1080/08870446.2011.613995

Ajzen, I., \& Manstead, A. (2007). Changing Health-Related Behaviors: An Approach Based on the Theory of Planned Behavior. In J. D. M. Hewstone (Ed.), The scope of social psychology: Theory and applications (pp. 43-63). New York: Psychology Press.

Albarracin, D. J. (2001). Theories of Reasoned Action and Planned Behavior as Models of Condom Use. Psychological Bulletin, 127, 142-161. http://dx.doi.org/10.1037/0033-2909.127.1.142

Amireault, S., Godin, G., Vohl, M. C., \& Pérusse, L. (2008). Moderators of the Intention-Behaviour and Perceived Behavioural Control-Behaviour Relationships for Leisure-Time Physical Activity. International Journal of Behavioral Nutrition and Physical Activity, 5, 7. http://dx.doi.org/10.1186/1479-5868-5-7

Armitage, C., \& Conner, M. (2001). Efficacy of the Theory of Planned Behaviour: A Meta-Analytic Review. British Journal of Social Psychology, 40, 471-499. http://dx.doi.org/10.1348/014466601164939

Armitage, C., \& Cornner, M. (1999). Distinguishing Perceptions of Control from Self-Efficacy: Predicting Consumption of a Low-Fat Diet Using the Theory of Planned Behavior. Journal of Applied Social Psychology, 29, 72-90.

http://dx.doi.org/10.1111/j.1559-1816.1999.tb01375.x

Arnow, B. K. (1995). The Emotional Eating Scale: The Development of a Measure to Assess Coping with Negative Affect by Eating. International Journal of Eating Disorders, 18, 79-90. http://dx.doi.org/10.1002/1098-108X(199507)18:1<79::AID-EAT2260180109>3.0.CO;2-V

Åstrøm, A., \& Rise, J. (2001). Young Adults' Intention to Eat Healthy Food: Extending the Theory of Planned Behaviour. Psychology \& Health, 16, 223-237. http://dx.doi.org/10.1080/08870440108405501

Bebetsos, E., Chroni, S., \& Theodorakis, Y. (2002). Physical Active Students' Intentions and Self-Efficacy towards Healthy Eating. Psychological Reports, 91, 485-495.

Bebetsos, E., Theodorakis, I., Laparidis, K., \& Chroni, S. (2000). Reliability and Validity of a Self-Confidence Scale for a 
Healthy Eating Questionnaire. Health and Sport Performance, 3, 191-203. (In Greek)

Boudreau, F., \& Godin, G. (2007). Using the Theory of Planned Behaviour to Predict Exercise Intention in Obese Adults. Canadian Journal of Nursing Research, 39, 112-125.

Bozionelos, G. (1999). The Theory of Planned Behaviour as Predictor of Exercise. Journal of Health Psychology, 4, 517-529. http://dx.doi.org/10.1177/135910539900400406

Bray, G. A., \& Bouchard, C. (2014). Handbook of Obesity: Epidemiology, Etiology, and Physiopathology. Boca Raton: CRC Press. http://dx.doi.org/10.1201/b16473

Catellier, A., \& Yang, Z. (2013). The Role of Affect in the Decision to Exercise: Does Being Happy Lead to a More Active Lifestyle? Psychology of Sport and Exercise, 14, 275-282. http://dx.doi.org/10.1016/j.psychsport.2012.11.006

Clark, J. (2015). Diet, Exercise or Diet with Exercise: Comparing the Effectiveness of Treatment Options for Weight-Loss and Changes in Fitness for Adults (18-65 Years Old) Who Are Overfat, or Obese; Systematic Review and Meta-Analysis. Journal of Diabetes \& Metabolic Disorders, 14, 31.

Conner, M., Norman, P., \& Bell, R. (2002). The Theory of Planned Behavior and Healthy Eating. Health Psychology, 21, 194-201. http://dx.doi.org/10.1037/0278-6133.21.2.194

Connolly, C., Romano, T., \& Patruno, M. (1998). Effects of Dieting and Exercise on Resting Metabolic Rate and Implications for Weight Management. Family Practice, 16, 196-201.

Deforche, B., De Bourdeaudhuij, I., \& Tanghe, A. (2006). Attitude toward Physical Activity in Normal-Weight, Overweight and Obese Adolescents. Journal of Adolescent Health, 38, 560-568. http://dx.doi.org/10.1016/j.jadohealth.2005.01.015

Gardner, R., \& Hausenblas, H. (2005). Exercise and Diet Determinants of Overweight Women Participating in an Exercise and Diet Program: A Prospective Examination of the Theory of Planned Behavior. Women \& Health, 42, 37-62. http://dx.doi.org/10.1300/J013v42n04_03

Gelman, A. H. (2006). Data Analysis Using Regression and Multilevel/Hierarchical Models. Cambridge: Cambridge University Press. http://dx.doi.org/10.1017/cbo9780511790942

Ghahremani, L., Niknami, S., \& Nazari, M. (2012). The Prediction of Physical Activity Intention and Behavior in Elderly Male Residents of a Nursing Home: A Comparison of Two Behavioral Theories. Iranian Journal of Medical Sciences, 37 , 23-31.

Godin, G., \& Kok, G. (1996). The Theory of Planned Behavior: A Review of Its Applications to Health-related Behaviors. American Journal of Health Promotion, 11, 87-98. http://dx.doi.org/10.4278/0890-1171-11.2.87

Godin, G., \& Shephard, R. (1985). A Simple Method to Assess Exercise Behavior in the Community. Canadian Journal of Applied Sport Sciences, 10, 141-146.

Godin, G., Amireault, S., Bélanger-Gravel, A., Vohl, M., \& Pérusse, L. (2009). Prediction of Leisure-Time Physical Activity Among Obese Individuals. Obesity, 17, 706-712. http://dx.doi.org/10.1038/oby.2008.599

Godin, G., Bélanger-Gravel, A., \& Nolin, B. (2008). Mechanism by Which BMI Influences Leisure-Time Physical Activity Behavior. Obesity (Silver Spring), 16, 1314-1317. http://dx.doi.org/10.1038/oby.2008.219

Godin, G., Bélanger-Gravel, A., Vohl, M., \& Pérusse, L. (2011). The Effect of Mere-Measurement of Cognitions on Physical Activity Behavior: A Randomized Controlled Trial among Overweight and Obese Individuals. International Journal of Behavioral Nutrition and Physical Activity, 8, 2. http://dx.doi.org/10.1186/1479-5868-8-2

Grønhøj, A., Bech-Larsen, T., Chan, K., \& Tsang, L. (2013). Using Theory of Planned Behavior to Predict Healthy Eating Among Danish Adolescents. Health Education, 113, 4-17. http://dx.doi.org/10.1108/09654281311293600

Guillaumie, L., Godin, G., \& Vezina-Im, L. (2010). Psychosocial Determinants of Fruit and Vegetable Intake in Adult Population: A Systematic Review. International Journal of Behavioral Nutrition and Physical Activity, 7, 12. http://dx.doi.org/10.1186/1479-5868-7-12

Hagger, M., Chatzisarantis, N., \& Biddle, S. (2002). A Meta-Analytic Review of the Theories of Reasoned Action and Planned Behavior in Physical Activity Q Predictive Validity and the Contribution of Additional Variables. Exercise Psychology, 24, 3-32.

Hardeman, W., Johnston, M., Bonetti, D., Wareham, N., \& Kinmonth, A. (2002). Application of the Theory of Planned Behaviour in Behaviour Change Interventions: A Systematic Review. Psychology \& Health, 17, 123-158. http://dx.doi.org/10.1080/08870440290013644a

Hassandra, M., Vlachopoulos, S., Kosmidou, E., Hatzigeorgiadis, A., Goudas, M., \& Theodorakis, Y. (2011). Predicting Students' Intention to Smoke by Theory of Planned Behaviour Variables and Parental Influences across School Grade Levels. Psychology \& Health, 26, 1241-1258. http://dx.doi.org/10.1080/08870446.2011.605137

Hearty, A., McCarthy, S., Kearney, J., \& Gibney, M. (2007). Relationship between Attitudes towards Healthy Eating and Dietary Behaviour, Lifestyle and Demographic Factors in a Representative Sample of Irish Adults. Appetite, 48, 1-11. http://dx.doi.org/10.1016/j.appet.2006.03.329 
Hill, J. P. (1998). Environmental Contributions to the Obesity Epidemic. Science, 280, 1371-1374. http://dx.doi.org/10.1126/science.280.5368.1371

Hyde, A. L., Conroy, D. E., \& Pincus, A. L. (2011). Unpacking the Feel-Good Effect of Free-Time Physical Activity: Between- and Within-Person Associations with Pleasant-Activated Feeling States. Journal of Sport and Exercise Psychology, 33, 884-902.

Karvinen, K., Courneya, K., Campbell, K., Pearcey, R., Dundas, G., Capstick, V. et al. (2007). Correlates of Exercise Motivation and Behavior in a Population-Based Sample of Endometrial Cancer Survivors: An Application of the Theory of Planned Behavior. International Journal of Behavioral Nutrition and Physical Activity, 4, 21. http://dx.doi.org/10.1186/1479-5868-4-21

Kim, K., Reicks, M., \& Sjoberg, S. (2003). Applying the Theory of Planned Behavior to Predict Dairy Product Consumption by Older Adults. Journal of Nutrition Education and Behavior, 35, 294-301. http://dx.doi.org/10.1016/s1499-4046(06)60343-6

McClure, A., Tanski, S., Kingsbury, J., Gerrard, M., \& Sargent, J. (2010). Characteristics Associated with Low Self-Esteem among US Adolescents. Academic Pediatrics, 10, 238-244. http://dx.doi.org/10.1016/j.acap.2010.03.007

McEachan, R., Conner, M., Taylor, N., \& Lawton, R. (2011). Prospective Prediction of Health-Related Behaviours with the Theory of Planned Behaviour: A Meta-Analysis. Health Psychology Review, 5, 97-144. http://dx.doi.org/10.1080/17437199.2010.521684

Michie, S., Ashford, S., Sniehotta, F., \& Dombrowski, S. (2011). A Refined Taxonomy of Behaviour Change Techniques to Help People Change Their Physical Activity and Healthy Eating Behaviours: The CALO-RE Taxonomy. Psychology Health, 26, 1479-1498. http://dx.doi.org/10.1080/08870446.2010.540664

Miller, W., \& Miller, T. (2010). Attitudes of Overweight and Normal Weight Adults Regarding Exercise at a Health Club. Journal of Nutrition Education and Behavior, 42, 2-9. http://dx.doi.org/10.1016/j.jneb.2008.08.005

Mogre, V., Nyaba, R., Aleyira, S., \& Sam, N. (2015). Demographic, Dietary and Physical Activity Predictors of General and Abdominal Obesity among University Students: A Cross-Sectional Study. Springerplus, 4, 226. http://dx.doi.org/10.1186/s40064-015-0999-2

Nestle, M. P. (2013). How the Food Industry Influences Nutrition and Health. Oakland, CA: University of California Press.

Norman, P. C. (1999). The Theory of Planned Behavior and Smoking Cessation. Health Psychology, 18, 89-94. http://dx.doi.org/10.1037/0278-6133.18.1.89

Øygard, L., \& Rise, J. (1996). Predicting the Intention to Eat Healthier Food among Young Adults. Health Education Research, 11, 453-461. http://dx.doi.org/10.1093/her/11.4.453

Payne, N., Jones, F., \& Harris, P. (2004). The Role of Perceived Need within the Theory of Planned Behaviour: A Comparison of Exercise and Healthy Eating. British Journal of Health Psychology, 9, 489-504. http://dx.doi.org/10.1348/1359107042304524

Payne, N., Jones, F., \& Harris, P. (2005). The Impact of Job Strain on the Predictive Validity of the Theory of Planned Behaviour: An Investigation of Exercise and Healthy Eating. The British Psychological Society, 10, 115-131. http://dx.doi.org/10.1348/135910704x14636

Plotnikoff, R., Lubans, D., Costigan, S., \& McCargar, L. (2013). A Test of the Theory of Planned Behavior to Predict Physical Activity in an Overweight/Obese Population Sample of Adolescents from Alberta, Canada. Health Education and Behavior, 40, 415-425. http://dx.doi.org/10.1177/1090198112455642

Povey, R., Conner, M., Sparks, P., James, R., \& Shepherd, R. (2000). The Theory of Planned Behaviour and Healthy Eating: Examining Additive and Moderating Effects of Social Influence Variables. Psychology \& Health, 14, 991-1006. http://dx.doi.org/10.1080/08870440008407363

Psouni, S., Hassandra, M., \& Theodorakis, Y. (2016). Patterns of Eating and Physical Activity Attitudes and Behaviors in Relation to Body Mass Index. Psychology, 7, 180-192. http://dx.doi.org/10.4236/psych.2016.72020

Puhl, R., \& Heuer, C. (2009). The Stigma of Obesity: A Review and Update. Obesity, 17, 941-964. http://dx.doi.org/10.1038/oby.2008.636

Rhodes, E., \& Dickau, L. (2013). Moderators of the Intention-Behavior Relationship in the Physical Activity Domain: A Systematic Review. British Journal of Sports Medicine, 47, 215-225. http://dx.doi.org/10.1136/bjsports-2011-090411

Rivis, A., \& Sheeran, P. (2003). Descriptive Norms as an Additional Predictor in the Theory of Planned Behavior: A Meta-Analysis. Current Psychology Developmental, Learning, Personality, Social, 22, 218-233.

Rothman, K.J. (2008). BMI-Related Errors in the Measurement of Obesity. International Journal of Obesity, 3, 56-59. http://dx.doi.org/10.1038/ijo.2008.87

Schifter, D., \& Ajzen, I. (1985). Intention, Perceived Control, and Weight Loss: An Application of the Theory of Planned Behavior. Journal of Personality and Social Psychology, 49, 843-851. http://dx.doi.org/10.1037/0022-3514.49.3.843 
Sjoberg, S., Kim, K., \& Reicks, M. (2004). Applying the Theory of Planned Behavior to Fruit and Vegetable Consumption by Older Adults. Journal of Nutrition for the Elderly, 23, 35-46. http://dx.doi.org/10.1300/J052v23n04_03

Sutton, S. (1998). Predicting and Explaining Intentions and Behavior: How Well Are We Doing? Journal of Applied Social Psychology, 28, 1317-1338. http://dx.doi.org/10.1111/j.1559-1816.1998.tb01679.x

Theodorakis, Y. (1994). Planned Behavior, Attitude Strength, Role Identity, and the Prediction of Exercise Behavior. Sport Psychologist, 8, 149-165.

Thomas, E. L., Frost, G., Taylor-Robinson, S. D., \& Bell, J. D. (2012). Excess Body Fat in Obese and Normal-Weight Subjects. Nutrition Research Reviews, 25, 150-161. http://dx.doi.org/10.1017/S0954422412000054

Trudeau, E., Kristal, A., Li, S., \& Patterson, S. (1998). Demographic and Psychosocial Predictors of Fruit and Vegetable Intakes Differ: Implications for Dietary Interventions. Journal of the American Dietetic Association, 98, 1412-1417. http://dx.doi.org/10.1016/S0002-8223(98)00319-8

Verplanken, B., \& Faes, S. (1999). Good Intentions, Bad Habits, and Effects of Forming Implementation Intentions on Healthy Eating. European Journal of Social Psychology, 29, 591-604.

http://dx.doi.org/10.1002/(SICI)1099-0992(199908/09)29:5/6<591::AID-EJSP948>3.0.CO;2-H

Wing, R., \& Phelan, S. (2005). Long-Term Weight Loss Maintenance1,2,3,4. American Journal of Clinical Nutrition, 82, 222S-225S. 